\title{
The presynaptic machinery at the synapse of C. elegans
}

\author{
Fernando Calahorro ${ }^{1}$ (1) . Patricia G. Izquierdo ${ }^{1}$
}

Received: 2 November 2017 / Accepted: 22 February 2018 / Published online: 12 March 2018

(c) The Author(s) 2018

\begin{abstract}
Synapses are specialized contact sites that mediate information flow between neurons and their targets. Important physical interactions across the synapse are mediated by synaptic adhesion molecules. These adhesions regulate formation of synapses during development and play a role during mature synaptic function. Importantly, genes regulating synaptogenesis and axon regeneration are conserved across the animal phyla. Genetic screens in the nematode Caenorhabditis elegans have identified a number of molecules required for synapse patterning and assembly. C. elegans is able to survive even with its neuronal function severely compromised. This is in comparison with Drosophila and mice where increased complexity makes them less tolerant to impaired function. Although this fact may reflect differences in the function of the homologous proteins in the synapses between these organisms, the most likely interpretation is that many of these components are equally important, but not absolutely essential, for synaptic transmission to support the relatively undemanding life style of laboratory maintained C. elegans. Here, we review research on the major group of synaptic proteins, involved in the presynaptic machinery in $C$. elegans, showing a strong conservation between higher organisms and highlight how C. elegans can be used as an informative tool for dissecting synaptic components, based on a simple nervous system organization.
\end{abstract}

Keywords $C$. elegans $\cdot$ Synapse $\cdot$ Synaptic proteins $\cdot$ Synaptogenesis $\cdot$ Synaptic vesicles

\section{Background}

Transmission of a signal within a neuron is carried by depolarization of the resting membrane potential typically involving a transient reversal of the resting membrane potential. The depolarization leads to the opening of voltage-gated $\mathrm{Ca}^{2+}$ channels in the presynaptic membrane. Then, the opening of these channels causes a rapid influx of $\mathrm{Ca}^{2+}$ into the presynaptic terminal, facilitating synaptic vesicles fusion with the presynaptic plasma membrane of the neuron, and causing neurotransmitters to be released into the synaptic cleft. Neurotransmitters in the synaptic cleft diffuse away from the release site and have ready access to binding sites on synaptic receptors localized on both the post- and presynaptic membrane. They bind to their cognate receptors and elicit a transduction cascade to bring about the cellular response. In nerve terminals, neurotransmitters are packaged into synaptic vesicles $(\mathrm{SVs})$ and released by $\mathrm{Ca}^{2+}$-induced

Fernando Calahorro

F.Calahorro@soton.ac.uk

1 Biological Sciences, University of Southampton, Life Sciences Building 85, Southampton SO17 1BJ, UK exocytosis (Katz 1971, 1979; Sudhof 2004). A precise neuronal reaction requires that $\mathrm{SVs}$ are clustered adjacent to the release site or presynaptic active zone. Here the SVs are docked and held in contact with the cell membrane by the docking complex, where they are primed for fusion. Then, a depolarization induces the opening of $\mathrm{Ca}^{2+}$ channels, and the rising $\mathrm{Ca}^{2+}$ concentration stimulates SV-plasma membrane fusion. For cells to respond rapidly and reliably to incoming depolarizing potentials, they must maintain a sufficient supply of vesicles containing neurotransmitter close to the active zone where the content is released from the presynaptic neuron. However, there are neurons that use only graded voltage signals. These 'non-spiking' neurons that encode information as graded potentials typically have higher information rates compared to 'spiking neurons' (DiCaprio et al. 2007). Graded potentials are a consequence of the passive electrical property of the membrane and depolarizing potentials the result of a coordinated response (van Steveninck and Laughlin 1996). Finally, neurotransmitter release can occur by action potential-independent spontaneous vesicle fusion. Although for decades it was thought that spontaneous transmission was a consequence of 'leaky' synapse, recent data show that this alternative mechanism underpins signalling 
roles involve in synapse maturation and homoeostatic plasticity (Ramirez and Kavalali 2011).

Neurotransmitters are secreted from neurons by two types of vesicles that are classified by their size and appearance in electron micrographs. Small clear synaptic vesicles (SCV) (40-60 nm diameter) contain small molecule, so-called classical transmitters, such as glutamate, GABA and acetylcholine, that activate postsynaptic ionotropic receptors mediating fast synaptic transmission, and metabotropic receptors mediating a more slow and sustained transmission. Densecore vesicles (DCVs) (60-120 nm diameter) are characterized by their electron dense appearance and larger diameter relative to SCVs, containing neuropeptides and biogenic amine neuromodulators such as serotonin and dopamine. DCVs dock at the plasma membrane but might be excluded from active zones (Hammarlund et al. 2008). There are similarities in the fusion machinery for both vesicle types, but also there are differences in the kinetics of exocytosis, docking localization and physiological regulation of release (Martin 2003; Rettig and Neher 2002), suggesting that there are proteins and mechanisms that are distinct for SCV- and DCV-mediated exocytosis.

Current models describing the molecular mechanism of $\mathrm{Ca}^{2+}$-regulated synaptic vesicle exocytosis and endocytosis divide the process into multiple steps, leading 'preferred' models: docking, priming, fusion, exocytosis (Fig. 1) (Jung and Haucke 2007; Sudhof 1995, 2004). This process is facilitated by the formation of a complex between molecules on the synaptic vesicle and molecules attached to the plasma membrane. $\mathrm{Ca}^{2+}$ binding to synaptotagmin triggers release by stimulating synaptotagmin binding to a molecular complex composed of SNARE ('soluble NSF attachment receptor') and SM ('Sec1/Munc18-like') proteins that mediates membrane fusion during exocytosis. Synaptic vesicles containing synaptotagmin are positioned at the active zone, the site of vesicle fusion, by a protein complex containing RIM proteins. RIM proteins simultaneously activate docking and priming of synaptic vesicles and recruit $\mathrm{Ca}^{2+}$ channels to active zones, thereby connecting within a single complex the primed synaptic vesicles to $\mathrm{Ca}^{2+}$ channels. This architecture allows direct flow of $\mathrm{Ca}^{2+}$ ions from $\mathrm{Ca}^{2+}$ channels to synaptotagmin, mediating tight millisecond coupling of a depolarization to neurotransmitter release. Influx of $\mathrm{Ca}^{2+}$ then leads to the rapid completion of membrane fusion and the release of the neurotransmitter (Rizo and Sudhof 2002). Finally, after fusion the vesicular components are recycled through endocytosis to replenish the synaptic vesicle pools. Three functional and morphological classes of vesicle pools have been assigned: the readily releasable pool (docked at active zones and 'ready to go' upon stimulation), the recycling pool (scattered throughout the nerve terminals and recycling upon moderate stimulation) and finally the reserve pool (occupying most of the vesicle clusters and only recycling upon C strong stimulation) (Sudhof 2013).

Key insights into the molecular mechanisms of synaptic events have come from research using genetic model systems such as the nematode Caenorhabditis elegans (Richmond 2005). Of particular note are studies employing mutants with uncoordinated locomotion (unc genes) (Brenner 1974) to define key synaptic determinants, optogenetics coupled with high-pressure freezing to resolve the relationship between docking and fusion (Watanabe et al. 2013) and genetic manipulation of syntaxin to define priming events (McEwen and Kaplan 2008). Here we provide a review of regulated exocytosis in C. elegans by presynaptic elements, highlighting C. elegans synapse as a powerful tool to dissect synaptic components and understanding key synaptic processes. We comment on the opportunity for future research directions deploying this model organism.

\section{Attachment of vesicles to the cytoskeleton}

The principal synaptic protein which functions as a cytoskeleton anchor for vesicles in the reserve vesicle pool is synapsin (Fig. 2). Synapsins comprise a family of synaptic vesicle proteins that have been identified in a variety of invertebrate and vertebrate species (Stavoe et al. 2012; Cesca et al. 2010). In C. elegans, there is a homologue of synapsin protein (SNN-1) which is most similar to vertebrate synapsin II. In vertebrates, synapsins present highly conserved domains among the different isoforms. The best characterized domains are: domain A containing a phosphorylation site for PKA/CaMKI that regulates binding to synaptic vesicles, domain $\mathrm{C}$ containing ATP binding sites and domain $\mathrm{E}$ that regulates the reserve pool of synaptic vesicles. In C. elegans, snn-1 presents a conserved domain organization with PKA/CaMKI site within domain A, several ATP binding sites in domain $\mathrm{C}$ and a highly conserved domain $\mathrm{E}$ (Cesca et al. 2010). ssn- 1 is expressed in neurons exhibiting patterns consistent with localization to vesicles in presynaptic regions. Very little is known about the exact role of SNN-1 in C. elegans, since snn-1 mutants display predominantly wild-type phenotypes. However, a detailed analysis of specific synapses in snn-1 mutants reveals synaptic vesicle clustering defects in the sensory neuron AIY (Stavoe et al. 2012) and resistance to paralysis on aldicarb (Sieburth et al. 2005). This latter phenotype is indicative of reduced acetylcholine release at the body wall neuromuscular junction as the paralysis is induced by accumulation of acetylcholine in the presence of the cholinesterase inhibitor aldicarb. This assay has been extensively deployed to resolve genetic determinants of cholinergic transmission in C. elegans (Mahoney et al. 2006). 


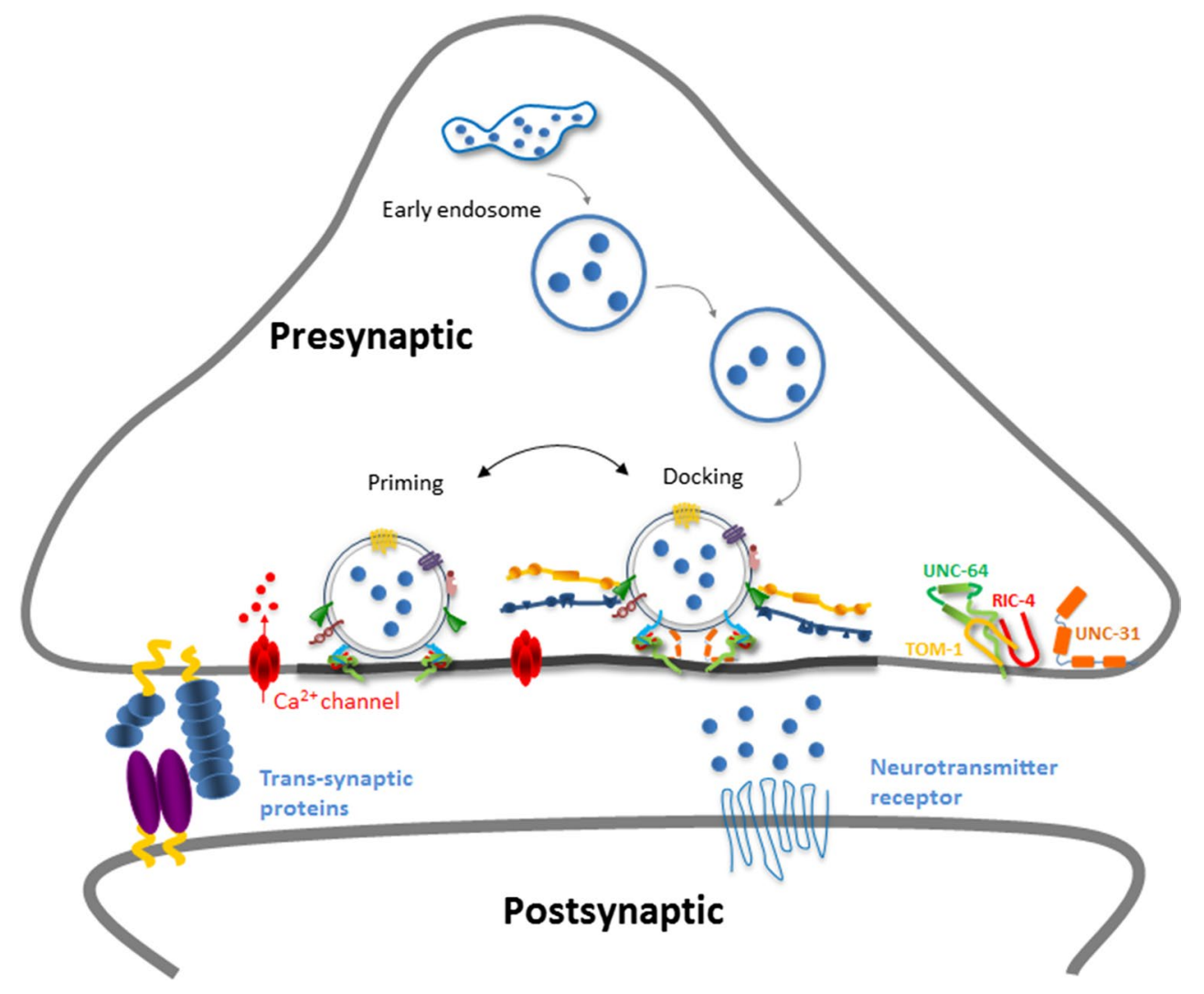

Fig. 1 Molecular mechanisms of biogenesis and exocytosis of synaptic vesicles. Under resting conditions, synaptic vesicles are stored in the cytoplasm of the nerve terminal. Vesicles are loaded with neurotransmitter through an active processes requiring a neurotransmitter transporter and a vacuolar-type proton pump ATPase that provides a $\mathrm{pH}$ and electrochemical gradient. These transporters are selective for different classes of transmitters. The identity of many of these transporters was determined through the molecular characterization of $C$. elegans mutants. Filled vesicles dock at the active zone (represented by a thick grey line), where they undergo a priming reaction that makes them competent for $\mathrm{Ca}^{2+}$-triggered fusion-pore opening. Priming involves all steps required to acquire release preparation of the exocytosis complex. In special situations-i.e., during sustained activity, the priming could precede docking, resulting in immediate fusion of vesicles. After exocytosis, the vesicle proteins remain clustered in the plasma membrane to be recycled by endocytosis. The double arrow between docking and priming representations indicates that priming can precede docking instead to the interpretations

The synaptic vesicle clustering in mammals is regulated by F-actin protein through two different pathways, one dependent on synapsins and the other independent (Nelson et al. 2013). In mammals, the synapsin family consists of at least 9 isoforms encoded by 3 distinct genes which are characterized by a mosaic of conserved and variable domains (Fornasiero et al. 2010). Specifically, the $\mathrm{N}$-terminal portion of all synapsins is highly conserved, whereas the C-terminal portion is variable because of heterogeneous combinations of two different domains (Kao et al. 1999; Porton et al. 2011). Synapsins are vesicle based on 'preferred' models where docking is before priming. The last interpretation is supported by evidence, among others, such as $r a b-3$ and $u n c-18$ knockouts present an alteration in vesicle docking although the docking is not completely disrupted (Nonet et al. 1997; Weimer et al. 2003). Finally, synaptic vesicles are regenerated within the nerve terminal probably through one of the three proposed pathways (not shown in the diagram): a pathway in which vesicles endocytose by closure of the fusion pore and are refilled with neurotransmitters while remaining docked to the active zone (kiss-and-stay); a local recycling pathway that is clathrin independent but results in mixing vesicles with the reserve pool after endocytosis (kiss-andrun); and a pathway whereby vesicles undergo clathrin-mediated endocytosis and recycle either directly or via endosomes, ultrafast endocytosis removes membrane added by vesicle fusion at the lateral edge of the active zone. Large endocytic vesicles then fuse to endosomes, and in this way, newly formed synaptic vesicles can be recruited back to the active zone

proteins that link synaptic vesicles to the presynaptic cytoskeletal matrix by interacting with actin (Bahler and Greengard 1987; De Camilli et al. 1983; Li et al. 1995). They are expressed in neurons exhibiting patterns consistent with localization to vesicles in presynaptic regions (Sieburth et al. 2005), having multiple functions within presynaptic terminals, including anchoring of synaptic vesicles to the actin cytoskeleton, recruitment of them to a reserve pool and regulation of the fusion of SVs (De Camilli et al. 1990; Pieribone et al. 1995; Hilfiker et al. 1998). They are also implicated in neuronal development, 


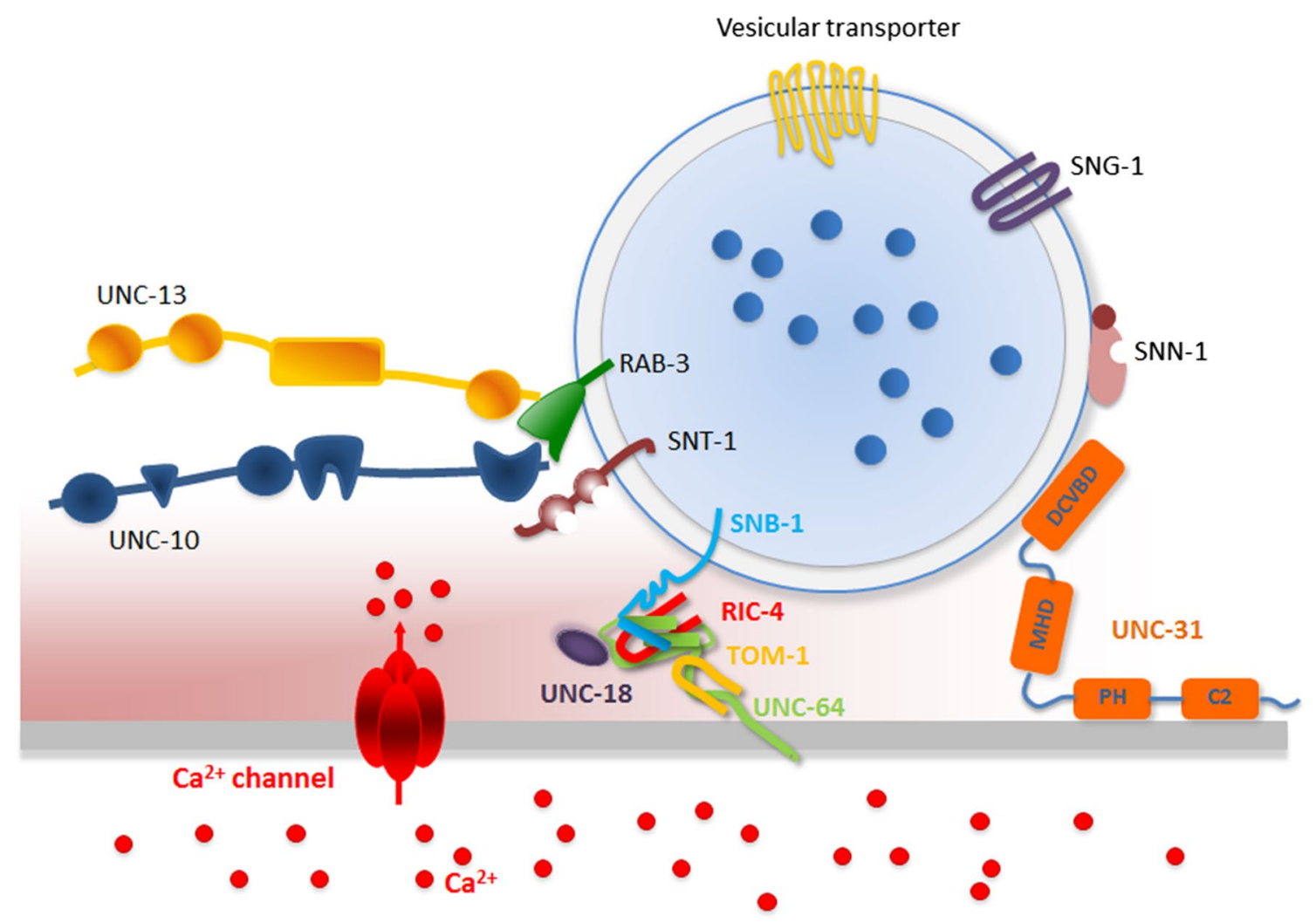

Fig. 2 Molecular protein complexes that organize the secretory machinery at the presynaptic active zone. The vesicle clusters dock at the active zone through Rab proteins, CAPs protein (UNC-31), Munc-18 (UNC-18) and tomosyn. RIM (UNC-10) protein places the priming factor Munc-13 and $\mathrm{Ca}^{2+}$ channels into close proximity to synaptic vesicles and SNARE protein complex-dependent (synaptobrevin, SNAP-25, syntaxin) fusion machinery. In addition to $\mathrm{Ca}^{2+}$

synaptogenesis and maintenance of mature synapses (Ferreira et al. 2000).

Studies in mice show that mutants lacking synapsin I appear to develop normally and do not have gross anatomical abnormalities. However, in these mutants, the giant fibre terminals, in the CA3 area of the hippocampus, are significantly smaller, the number of synaptic vesicles is reduced, and the presynaptic structures altered (Takei et al. 1995). Furthermore, suppression of synapsin II leads to an inhibition of developing and synapse formation in hippocampal neurons. Similarly, a depletion of synapsin III affects the extension of processes and axon differentiation in hippocampal neurons (Bloom et al. 2003; Ferreira et al. 1995, 2000; Takei et al. 1995).

\section{Docking}

The vesicle cluster that represents the reserve pool dock at the active zone through a subset of synaptic proteins include Rab proteins, CAPs protein (UNC-31), Munc-18 (UNC-18) channels, RIM proteins directly bind to the vesicle protein Rab3, to the priming factor Munc-13. Munc-13 directly activates the SNARE protein assembly. Both RIM and Munc-13 proteins are tightly regulated in a manner that determines presynaptic plasticity. The diagram is based on the Sudhof's synaptic model (Sudhof 2013) and represents a magnified view of vesicle docking shown in Fig. 1

and tomosyn (Fig. 2). Rab proteins present a key role regulating the recruitment of vesicles to the active zone in $C$. elegans. The Rab proteins are a large family of monomeric GTPases, conserved from yeast to humans, which through specific scaffolding with distinct interactors specify presynaptic function (Bock et al. 2001; Stenmark and Olkkonen 2001). In C. elegans, there are 31 members of the Rab family, 29 of which are also found in humans as orthologues (Gallegos et al. 2012). Probably, the most extensively studied Rab proteins in $C$. elegans are RAB-27/AEX-6 and RAB-3, homologues of human RAB-27 and RAB-3, respectively. $C$. elegans $r a b-27$ is expressed in neurons and in the intestine. In the nervous system, $r a b$-27 localizes to synapserich regions of the nervous system (nerve ring, dorsal and ventral cord) and partially co-localizes with synaptic vesicleassociated $r a b$-3, although RAB-27 immunostaining is normal in rab-3 mutants, suggesting that RAB-27 localization is independent of RAB-3 function (Mahoney et al. 2006). This expression profile is consistent with that of mammalian Rab27B, which is also expressed in both brain and intestine 
as well as other secretory cells. Both RAB-27 and RAB-3 present a key role in synaptic transmission process in $C$. elegans, regulating the recruitment of vesicles to the active zone or sequestration of vesicles near release sites (Mahoney et al. 2006). In vertebrates, Rab molecules regulate vesicular trafficking in many different transport pathways for both exocytosis and endocytosis in neural and non-neuronal tissues, but in C. elegans RAB-3 in neurons specifically plays a crucial role in regulating synaptic vesicle-mediated release (Nonet et al. 1997). As a consequence, C. elegans rab-3 mutants present slight behavioural abnormalities. They are resistant to the paralytic action of the cholinesterase inhibitor aldicarb suggesting that cholinergic transmission is generally depressed (Mahoney et al. 2006; Nonet et al. 1997), as well as exhibiting an altered morphology of neuromuscular junctions (Nonet et al. 1997). There is a depletion of $\approx 40 \%$ of normal levels in vesicle population at synapses (identified by electron microscopy) accompanied by an elevation of these populations in inter-synaptic regions of the axons consistent with a deficit in SCV trafficking (Mahoney et al. 2006; Nonet et al. 1997). In addition, extracellular electrophysiological recordings reveal an impairment of synaptic transmission in the pharyngeal nervous system (Nonet et al. 1997). There is only one isoform of rab-27 in C. elegans, while two isoforms are found in mammals. Like the $r a b$ 3 mutants, C. elegans rab-27 mutants are slightly aldicarb resistant indicative of a reduction in cholinergic signalling, and exhibiting defecation defects consistent with neuromuscular transmission dysfunction in anterior body wall muscle contraction and expulsion steps of the defecation motor program (Mahoney et al. 2006).

In humans, the number of Rab genes reaches up to 60 where 33 of them have been identified by proteomic analyses in synaptic vesicle fractions (Takamori et al. 2006). Of these, Rab-3A, 3B, 3C, 3D and 27-B are involved in exocytosis, while Rab-4, 5, 10, 11B and 14 are intermediates of synaptic vesicle recycling such as early endosomes (Binotti et al. 2016). Specifically, Rab-3A and Rab-27B are the best investigated and play overlapping roles during $\mathrm{Ca}^{2+}$-triggered neurotransmitter release in mammals (Schluter et al. 2002).

Another indispensable actor for synaptic vesicle-mediated exocytosis is UNC-31. This is also known as CAPS $\left(\mathrm{Ca}^{2+}\right.$-dependent activator protein for secretion) and is a multi-domain protein containing, from the $\mathrm{N}$ to the $\mathrm{C}$ terminus, a dynactin 1 binding domain (DBD), a $\mathrm{C} 2$ domain, a PH domain, a (M)UNC-13 homology domain (MHD) and finally a DCV binding domain (DCVBD) (Ann et al. 1997). The DBD is required for CAPS sorting (Sadakata et al. 2007b). The $\mathrm{C} 2$ domain, as a $\mathrm{Ca}^{2+}$ sensor, mediates $\mathrm{Ca}^{2+}$-dependent binding to phospholipids (Rizo and Sudhof 1998). The PH domain interacts with acidic phospholipids and binds with plasma membranes (Lemmon 2008). The MHD domain directly interacts with syntaxin, transforming syntaxin from the closed conformation into the open form giving the opportunity for syntaxin to form the SNARE core complex required for priming and docking (Basu et al. 2005; Betz et al. 1997; Hammarlund et al. 2008). Finally, the DCVBD domain mediates CAPS targeting to DCV (Grishanin et al. 2002).

CAPS was first identified as an essential protein for noradrenaline release from PC12 cells and recognized as being orthologous to C. elegans UNC-31 which had previously been shown to be involved in neurosecretion (Walent et al. 1992). As the name of the protein suggests, mutations in unc-31 result in uncoordinated motor behaviour and the worms are constitutively lethargic with slow and soft movements (Avery et al. 1993). In addition, unc-31 mutants feed constitutively and they have defects in egg laying and failures in recovery from dauer, a metabolically quiescent developmental larval stage of C. elegans (Avery et al. 1993; Dalliere et al. 2016). Consistent with this, the expression pattern of unc-31 reveals a broad distribution in the nervous system (Charlie et al. 2006).

UNC-31/CAPS has been associated with exocytosis mediated by DCVs (Berwin et al. 1998), and in line with this, in C. elegans it has been found that loss of the single isoform of UNC-31 decreases neuropeptide secretion accompanied by an increase in neuropeptide abundance in motor axons (Sieburth et al. 2007). Mammals express two isoforms of CAPS, CAPS1 and CAPS2, with similar functions but which differ in their spatiotemporal expression pattern (Sadakata et al. 2007c; Speidel et al. 2003). CAPS 1 is essential for the uptake or storage of catecholamines in DCVs (Speidel et al. 2005), while CAPS2 appears to be required for DCV-mediated neurotrophin secretion in the cerebellum (Sadakata et al. 2007a, c). In addition, in CAPS$1 / C A P S-2$ double null mutants DCV secretion is severely reduced (Farina et al. 2015). While early studies seemed to indicate that CAPS is not required for exocytosis of glutamate-containing SCVs (Tandon et al. 1998), this has been revised with further investigation that provides evidence for a more overlapping functional role with $\mathrm{SCV}$-mediated exocytosis. CAPS1 and CAPS2 double knockout mice exhibit specific priming defects in glutamatergic transmission (Jockusch et al. 2007). In Drosophila melanogaster, in which a single gene encodes $d C A P S$, there is a $\approx 50 \%$ loss in evoked glutamatergic transmission at the neuromuscular junction, as well as an accumulation of synaptic vesicles at active zones (Renden et al. 2001).

Munc-18 proteins are the mammalian homologue of UNC-18 proteins in C. elegans and are a member of the Sec1/Munc18-like (SM) protein family. Munc-18 is a key synaptic protein acting during multiple stages of the exocytosis including vesicle priming, docking and fusion. Although during these steps syntaxin interactions are required, Munc-18 also regulates vesicle fusion via 
syntaxin-independent interactions. These syntaxin interactions are possible through a Munc-18 closed conformation of syntaxin binding. In C. elegans, UNC-18 is a protein required in neurons for synaptic vesicle-mediated exocytosis. Characterization of unc- 18 reveals a localization in ventral-cord motor neurons and some unidentified head neurons in the adult hermaphrodite (Gengyo-Ando et al. 1993). A similar expression is observed in males, but also a strong expression in the gonad (Schindelman et al. 2006). unc-18 mutants are deficient in synaptic transmission with a reduction in neurotransmitter release and a consequent resistance to aldicarb (Graham et al. 2011; Gracheva et al. 2010). The introduction of a gain of function mutation in a functionally important domain ( $3 \mathrm{~b}$ ) within the UNC-18 protein confers a hypersensitivity to aldicarb (Graham et al. 2011). Munc18 has a function in several exocytosis processes requiring syntaxin-dependent interactions; however, data based on $C$. elegans studies reveal a key role of domain $3 \mathrm{~b}$ of Munc-18 in transducing regulation of vesicles fusion independent of closed-conformation syntaxin binding (Graham et al. 2011). This fact highlights C. elegans as a powerful and key tool to discover functional analysis of synaptic proteins, enhanced by the availability of CRISPR editing. Physiological data and electron micrographs of $C$. elegans neuromuscular junction provide evidence that in the absence of UNC-18 the size of the ready releasable pool of vesicles is drastically reduced (Weimer et al. 2003). Thus, unc-18 mutants present a reduction in docked vesicles at the active zone, indicating that UNC-18 functions as a facilitator of vesicle docking (Weimer et al. 2003). Overall, the release defects in unc-18 mutants are associated with the lack of two morphologically distinct vesicle pools: those tethered within $25 \mathrm{~nm}$ of the plasma membrane and those docked with the plasma membrane (Gracheva et al. 2010).

TOM-1 has also a role regulating the macromolecular complex binding between the SNARE proteins syntaxin, SNAP-25 and synaptobrevin, three synaptic molecules participating in the priming step. Tomosyn is a soluble protein first isolated from rat brain as a syntaxin binding partner capable of disrupting Munc18-syntaxin-1a complexes (Fujita et al. 1998). Tomosyn has two recognizable domains, an N-terminal domain rich in WD40 repeats and a C-terminal SNARE domain with high sequence homology to the R-SNARE domain of synaptobrevin (Hatsuzawa et al. 2003; Masuda et al. 1998). C. elegans tomosyn (TOM1 ) is a cytosolic syntaxin binding protein implicated in the modulation of both constitutive and regulated exocytosis that negatively regulates synaptic vesicle priming in C. elegans (Gracheva et al. 2006). Thus, tomosyn inhibits synaptic vesicle priming through its synaptobrevin SNARE motif, which forms an inhibitory SNARE complex with syntaxin and SNAP-25 (McEwen et al. 2006). The expression of tom$l$ is observed in ventral nerve cord motor neurons and in a subset of neurons in head and tail ganglia (Dybbs et al. 2005). The synapses in C. elegans tom- 1 mutants present no changes in neuronal outgrowth or in synaptogenesis but exhibit prolonged evoked postsynaptic responses. This latter phenotype is accompanied by an increase in the number of plasma membrane-contacting vesicles (Gracheva et al. 2006). Thus, tomosyn-deficient mutants have increased synaptic transmission, an increased pool of primed vesicles and increased abundance of UNC-13 (a synaptic protein involved in $\mathrm{Ca}^{2+}$-triggered fusion-pore opening described in the next sections) at synapses (McEwen et al. 2006). This indicates that priming is negatively regulated by TOM- 1 and that there is a fine balance between tomosyn and UNC-13, with the availability of open syntaxin a possible mechanism for this regulation (McEwen et al. 2006).

Overall, these findings from C. elegans along with studies using mouse models have shown tomosyn has a diffuse distribution in neurites and is accumulated at synapses colocalized with both moving SCVs and DCVs, regulating their mediated secretion. This suggests a function controlling the delivery, synaptic sharing and secretion of neuronal signalling molecules (Geerts et al. 2017).

\section{Priming}

After the docking of vesicles at the active zone, they undergo a priming reaction regulated by a few key synaptic elements, syntaxins (UNC-64), synaptobrevin (SNB-1) and SNAP-25 (RIC-4) (Fig. 2). Nevertheless, there might be a regulatory-coupled process between docking and priming of the synaptic vesicles (Fig. 1); namely, synapses lacking priming proteins, such as Munc-13 or SNARE, have a reduced or absence docking of vesicles (Imig et al. 2014). Syntaxins are a family of transmembrane proteins that participate in SNARE complexes to mediate membrane fusion events including exocytosis in different compartments of the nervous system such as axons, the soma/dendrites or astrocytes. In C. elegans, the unc-64 gene encodes syntaxin, a plasma membrane receptor for intracellular vesicles that is orthologous to vertebrate syntaxin 1A and Drosophila Syx1A. It is expressed in neural cells, especially in motor neurons and neurons constituting head ganglions (Ogawa et al. 1998; Yamashita et al. 2009). UNC-64 is required for normal locomotion and possibly also for insulin secretion and is an essential component of the core synaptic vesicle fusion machinery (McEwen and Kaplan 2008). UNC-64 interacts with UNC-13, UNC-18 and SNB-1/synaptobrevin (Sassa et al. 1999). Thus, it has been shown that loss of the $\mathrm{N}$-terminal binding interaction between the syntaxin UNC64 and the protein UNC-18 severely impairs neuromuscular synaptic transmission in C. elegans, resulting in an uncoordinated phenotype (Munson and Bryant 2009). In addition, 
unc-64-null mutants are unable to move and develop beyond the first larval stage (Saifee et al. 1998). C. elegans unc-64 and mammalian syntaxin-1A are functional orthologues as shown by the observation that unc-64-null mutant worms expressing the mammalian syntaxin-1A wild type are able to move, grow and reproduce (Park et al. 2016). Another example of the power of $C$. elegans to further analyse, in this case, the structure/function relationship of syntaxin-1, is the recent discovery that syntaxin-1 N-peptide is critical when syntaxin adopts an 'open' conformation to bend towards Munc-18 (Park et al. 2016).

Similar to C. elegans, mammalian syntaxins present a typical domain organization where the $\mathrm{N}$-terminal region contains two different motifs: a short $\mathrm{N}$-terminal peptide ('N-peptide') that binds to Munc18-1 (Dulubova et al. 2007), and a larger $\mathrm{H}_{\mathrm{abc}}$-domain that consists of an autonomously folded three-helical bundle (Bracher and Weissenhorn 2004). Perhaps, the best-studied membrane-fusion complex is that mediating synaptic vesicle fusion through syntaxin 1A/1B (Teng et al. 2001). It has been suggested that STX1A and STX1B are functionally redundant. Thus, STX1A KO mice show a normal lifespan, and hippocampal neurons with normal neurotransmission, indicating that STX1B functionally compensates the function of STX1A (Fujiwara et al. 2006; Gerber et al. 2008). However, complete loss or partial loss of STX1B in mice caused a pre-weaning death, suggesting that STX1A and STX1B have differential functions (Mishima et al. 2014).

Synaptobrevins are vesicle-associated proteins involved in neurotransmitter release (Nonet et al. 1998). In C. elegans, SNB-1 is broadly present in nervous system, in neurons in the head ganglia and motor neurons in ventral nerve cord. Particularly, the abundance of SNB-1 in GABAergic motor neurons is controlled by MEC-15, one of a small number of F-box proteins evolutionarily conserved from $C$. elegans to mammal (Sun et al. 2013). C. elegans null snb-1 mutants are not viable and die soon after hatching (Nonet et al. 1998). In an attempt to generate viable $C$. elegans snb-1-deficient mutants, the 197D substitution in snb-1(e1563) changes a hydrophobic residue to a charged residue in the TMD of synaptobrevin, leading to a synaptobrevin with reduction in function. snb-1 mutants carrying this substitution are viable, with grossly normal locomotion (Sandoval et al. 2006). These mutants are resistant to the acetylcholinesterase inhibitor aldicarb, indicating that cholinergic transmission is impaired, and present abnormal electropharyngeograms which are extracellular recordings of the pharyngeal neuromuscular network (Nonet et al. 1998).

Studies on synaptobrevins in mouse are difficult to carry out since synaptobrevin 1 and 2 mutants, the two isoforms extensively expressed in the central nervous system (Schoch et al. 2001), immediately die after birth (Nystuen et al. 2007; Schoch et al. 2001). In this sense, C. elegans has been a useful tool dissecting the role of synaptobrevins in neurotransmitter release. However, using high-density cultures of hippocampal neurons from embryos, a drastic reduction in $\mathrm{Ca}^{2+}$-triggered vesicle fusion has been observed (Schoch et al. 2001).

The SNAP protein family consists of several homologous proteins of which SNAP-25 is essential for SV fusion (Delgado-Martinez et al. 2007). The C. elegans orthologue of vertebrate $S N A P-25$, ric-4, appears to be expressed selectively in the nervous system including the nerve ring, commissures, and ventral and dorsal nerve cords (Hwang and Lee 2003). Little is known about the role of ric-4 at the $C$. elegans synapse; however, it is known that the loss of ric-4 function via RNAi experiments leads to aldicarb resistance, indicating that ric-4 plays a role in synapse structure and function (Sieburth et al. 2005). Studies using mouse models show that the deletion of SNAP-25 leads to reduced neuronal survival and impaired arborisation, reduced spontaneous release, and arrest of evoked release in the surviving neurons (Delgado-Martinez et al. 2007). In addition, the neurons of SNAP-25 null mutant mice (SNAP-25 KO) contain fewer DCVs and have reduced DCV fusion probability in surviving neurons at DIV14 (days in vitro). Others SNAP family members such us SNAP-23, SNAP-29 and SNAP-47 are also present in neurons and in synaptic vesicle purifications (Holt et al. 2006). Overexpression of SNAP-29 inhibits synaptic vesicle fusion possibly via inhibiting SNARE complex disassembly (Pan et al. 2005). Finally, SNAP-47 binds to plasma membrane SNAREs in vitro, but is predominantly located on intracellular membranes (Holt et al. 2006).

\section{lon channel regulation and fusion}

The priming reaction makes the vesicles competent for $\mathrm{Ca}^{2+}$-triggered fusion-pore opening. The major elements among the synaptic proteins involved in priming of SVs are synaptotagmin (SNT-1), synaptogyrin (SNG-1), Munc-13 (UNC-13) and RIM (UNC-10) (Fig. 2).

One key factor in $\mathrm{Ca}^{2+}$ regulation and vesicle fusion is the $\mathrm{Ca}^{2+}$ sensor synaptotagmin, which consists of a short N-terminal luminal segment, a single transmembrane $\alpha$-helix, an unstructured linker, and two $\mathrm{Ca}^{2+}$ binding $\mathrm{C} 2$ domains, termed C2A and C2B, respectively. In C. elegans, the two synaptotagmin isoforms, snt- $1 a$ and snt- $1 b$, are expressed in neurons, where snt- $1 a$ is typically expressed at higher levels and in a larger subset of neurons. In addition, snt- $1 b$ is exclusively expressed in the excretory duct cell and a subset of tail neurons including DVB, a GABAergic neuron required for defecation (Nonet et al. 1993; Mathews et al. 2007). Behaviourally, snt- 1 mutants present locomotory defects in swimming behaviour, as well as in the defecation motor program (Mathews et al. 2007). Evoked synaptic transmission 
is dependent on interactions between synaptotagmin and the SNARE complex, comprised of syntaxin, SNAP-25 and synaptobrevin. It has been shown that snt-1 C. elegans mutants present a significant reduction in this evoked transmission, indicating its key role in SNARE complex assembly (Yu et al. 2013). On the other hand, snt- 1 mutants present large irregular cisternae associated with abnormal endocytosis, indicating a defect impacting at this level of the vesicle cycle (Yu et al. 2013). In addition, morphometric analyses of NMJ (neuromuscular junction) in snt-1 mutants reveal a reduction in vesicle density, a phenotype associated with an endocytosis defect (Yu et al. 2013). snt-1 mutants also show a reduction in absolute numbers of docked vesicle, and this docking defect appeared to be a consequence of an overall reduced vesicle density, since the fraction of docked vesicles as a function of total vesicles in snt- 1 mutants was not significantly reduced compared to wild type (Yu et al. 2013). Both reductions in absolute docked vesicles and in evoked transmission suggest that SNT-1 has additional function beyond exocytosis, consistent with the well-documented role of snt-1 as a $\mathrm{Ca}^{2+}$ sensor promoting vesicle fusion (Yu et al. 2013). In addition, SNT-1 in C. elegans is crucial for the SVs (synaptic vesicles) association of RAB-3 protein. SNT-1 promotes the GTP-bound state of RAB-3 by inhibiting RAB-3 GAP, and thus, the catalytic subunit of RAB-3 GAP (RBG-1) localizes on SVs and directly binds to SNT-1 (Cheng et al. 2015). $\mathrm{Ca}^{2+}$ treatment disrupts the direct association between SNT-1 and RBG-1 (a Rab-3 GTPase). In addition, $\mathrm{Ca}^{2+}$ binding activity of SNT-1 is essential for the dissociation of RAB-3 from SVs (Cheng et al. 2015).

Complementary studies in mouse models have shown that synaptotagmins (specifically Syt1 and Syt2) are $\mathrm{Ca}^{2+}$ sensors for both synchronous and fast neurotransmitter release (Sun et al. 2007; Xu et al. 2009). Overall, synaptotagmins act as a cooperative $\mathrm{Ca}^{2+}$ receptor in exocytosis, binding $\mathrm{Ca}^{2+}$ at physiological concentrations. This binding is specific for $\mathrm{Ca}^{2+}$ and involves the cytoplasmic domain of synaptotagmin (Geppert et al. 1994; Pang et al. 2006).

Synaptogyrin and synaptophysin are tetraspan membrane proteins, the major vesicle proteins, characterized by four membrane-spanning domains that are tyrosine-phosphorylated (Arthur and Stowell 2007; Evans and Cousin 2005; Hubner et al. 2002). They are abundant and evolutionary conserved synaptic vesicle membrane proteins (Abraham et al. 2006) whose functions are poorly defined, and their depletion does not interfere with proper neuronal development and basic neuronal function in both $C$. elegans and mammals (Abraham et al. 2006; Eshkind and Leube 1995; McMahon et al. 1996). In contrast to vertebrates, in C. elegans the synaptogyrin but not the synaptophysin orthologue is predominant in neurons (Abraham et al. 2006; Hubner et al. 2002; Nonet 1999; Ruvinsky et al. 2007), expressed in all 26 GABAergic neurons, as well as in a subset of neurons across the nervous system (Abraham et al. 2011). In mouse and $C$. elegans, synaptogyrin is completely dispensable for nervous system development and performance of basic neuronal functions (Abraham et al. 2006; Eshkind and Leube 1995; McMahon et al. 1996). Thus, C. elegans mutants lacking or overexpressing synaptogyrin present an increased sensitivity to the epileptogenic GABA antagonist pentylenetetrazole (PTZ), showing a reduced convulsive threshold (Abraham et al. 2011). This suggests that modulation of the synaptic vesicle cycle is fine-tuned by the specific amount of synaptogyrin, since both decrease and increase in synaptogyrin result in an altered sensitivity to PTZ and aldicarb (Abraham et al. 2011). In addition, detailed analysis also uncovers mildly altered motility and decreased recruitment of synaptobrevin though not of RAB-3 to synapses, suggesting that synaptogyrin presents a distinct modulatory and redundant neuronal function in $C$. elegans (Abraham et al. 2011).

Another conserved core components of the presynaptic active zone are the UNC-13/Munc13 family. They are essential for both evoked and spontaneous SV release (Augustin et al. 1999; Richmond et al. 1999). These proteins contain multiple protein interaction domains and involved in many aspect aspects of presynaptic release. All the UNC13/Munc13 isoforms contain a diacylglycerol binding $\mathrm{C}_{1}$ domain followed by a MUN domain including the MHD (Munc13 homology domain) flanked by $\mathrm{C}_{2} \mathrm{~B}$ and $\mathrm{C}_{2} \mathrm{C}$ domains. The MUN domain, structurally similar to the vesicle tethering factors of the CATCHR (Complex Associated with Tethering Containing Helical rods) family (Li et al. 2011), is necessary for vesicle priming (Basu et al. 2005; Madison et al. 2005; Stevens et al. 2005) through binding to SNARE and Munc18 (Betz et al. 1997; Ma et al. 2011). The $\mathrm{N}$-terminal regions of UNC-13/Munc13 isoforms are divergent in amino acid sequences and have been hypothesized to contribute to the distinct properties of SV exocytosis in different types of synapses (Augustin et al. 2001; Rosenmund et al. 2002).

In $C$. elegans, the unc-13 locus produces two main isoforms that differ at the N-terminal region (Kohn et al. 2000). The expression of unc-13 is in all neurons of both head and tail ganglia, as well as ventral nerve cord (Maruyama et al. 2001). Using genetic mutations that eliminate function of all isoforms or only UNC-13L demonstrate an essential role of UNC-13L in neurotransmitter release (Richmond et al. 1999). The kinetic components of release are thought to be mediated by SVs in different spatial domains of the nerve terminal. Rapid (or synchronous) release occurs within a few milliseconds and is proposed to consist of fusion of $\mathrm{SVs}$ that are close to $\mathrm{Ca}^{2+}$ entry sites. However, slow release occurs over tens to hundreds of milliseconds and is thought to be mediated by fusion of SVs that are farther from $\mathrm{Ca}^{2+}$ channels (Neher and 
Sakaba 2008). In C. elegans, the UNC-13L isoform is colocalized at presynaptic terminals concentrated near dense projections. By contrast, the UNC-13S isoform presents a diffuse distribution in axons. This suggests that UNC-13L and UNC-13S may mediate different forms of release and distinct effects on synaptic transmission (Hu et al. 2013). In this sense, it has been shown that UNC-13L is involved in both fast and slow release of SVs, while the short isoform UNC-13S is required for the slow release (Hu et al. 2013). In more detail, other studies using a unique unc13 mutant that specifically deletes the $\mathrm{C}_{2} \mathrm{~A}$ domain of UNC-13L show that the precise position of UNC-13 in the active zone depended on the $\mathrm{C}_{2} \mathrm{~A}$ domain. In addition, the $\mathrm{C}_{2} \mathrm{~A}$ domain regulates the release probability of $\mathrm{SVs}$, likely through positioning UNC-13L to the active zone, and that this domain also has a significant influence in spontaneous release (Zhou et al. 2013). Importantly, early works using C. elegans have shown the role of PKC/DAG in the modulation of UNC-13. Thus, the binding of DAG by UNC-13 drives its membrane association and regulates the exocytosis function of UNC-13 (Lackner et al. 1999). Later, studies in Drosophila have also shown how the PLC and DAG modulation as well as G-proteins regulates the synaptic levels of DUNC-13, critical determinant of SV fusion probability (Aravamudan and Broadie 2003).

RIM proteins are presynaptic scaffolding proteins specifically localized to the active zone and found to bind several presynaptic proteins, like Munc13-1, Rab3a and voltage-gated $\mathrm{Ca}^{2+}$ channels (Betz et al. 2001; Kaeser et al. 2011; Schoch et al. 2002; Wang et al. 1997). RIM proteins are encoded by four genes (Rims 1-4); the Rim I and 2 genes give rise to five RIM isoforms, called RIM $1 \alpha$, RIM1 $\beta$, RIM2 $\alpha$, RIM2 $\beta$ and RIM2 $\gamma$ (Kaeser et al. 2008; Wang and Sudhof 2003). Studies using RIM1 $\alpha$ constitutive knockout mice and RIM mutants in C. elegans found roles for RIM1 in transmitter release, presumably via determining readily releasable vesicle pool size (Calakos et al. 2004; Koushika et al. 2001; Schoch et al. 2002). RIM mutants isolated in C. elegans (unc-10) are viable but exhibit behavioural and pharmacological defects, indicative of synaptic dysfunction according to the localization of RIM at the active zone. Although RIM was originally identified as a RAB-3 binding partner, the consequence of a loss of function mutation is more severe than $r a b-3$ mutants, suggesting that it possesses additional functions (Gracheva et al. 2008). Electrophysiological analysis of unc-10 worms revealed both reduced evoked release of SVs and spontaneous synaptic event frequency, thus implicating RIM in release (Koushika et al. 2001). UNC-10 is co-localized with the $\mathrm{Ca}^{2+}$ channel, UNC-2 at C. elegans presynaptic densities and synaptic release in unc-10 and rab-3 mutants exhibit reduced $\mathrm{Ca}^{2+}$ sensitivity (Gracheva et al. 2008a).

\section{Concluding remarks}

Through this review, we discussed the synaptic release machinery, and how the powerful genetic model C. elegans contributes to elucidating core processes of synaptic transmission. This is facilitated by the ability to maintain viable mutants of $C$. elegans for synaptic proteins that are otherwise essential in mice. It has broad relevance as $C$. elegans harbours the same elaborate elements for neurotransmission as mammals, and thus, it has been instrumental in key discoveries relating to the synaptic vesicle cycle. However, some key processes have yet to be elucidated; for example, the precise physicochemical mechanisms underlying fusion, the roles of key synaptic proteins with overlapping functions within complex neural networks and understanding how synaptic vesicles recaptured by clathrin-mediated endocytosis are placed back into the vesicle pool; all these aspects demand further study which may be supported by the $C$. elegans model. Advances in techniques to study the vesicle cycle in the intact living synapse in combination with genetic manipulation will accelerate progress in the field, shedding more light on these intricate processes. In this sense, C. elegans is an excellent system to facilitate discovery in this field, thanks to a simple, genetically tractable nervous system that is evolutionarily conserved with mammalian neurons, as well as providing new routes to understand the dynamic processes underlying neurotransmitter exocytosis.

Acknowledgements We would like to apologize to the colleagues whose work could not be cited due to space constraints. We are very grateful to Lindy Holden-Dye and Vincent O'Connor for their critical discussion and comments.

\section{Compliance with ethical standards}

Conflict of interest The authors declare that they have no competing interests.

Open Access This article is distributed under the terms of the Creative Commons Attribution 4.0 International License (http://creativeco mmons.org/licenses/by/4.0/), which permits unrestricted use, distribution, and reproduction in any medium, provided you give appropriate credit to the original author(s) and the source, provide a link to the Creative Commons license, and indicate if changes were made.

\section{References}

Abraham C, Hutter H, Palfreyman MT, Spatkowski G, Weimer RM, Windoffer R et al (2006) Synaptic tetraspan vesicle membrane proteins are conserved but not needed for synaptogenesis and neuronal function in Caenorhabditis elegans. Proc Natl Acad Sci U S A 103(21):8227-8232. https://doi.org/10.1073/ pnas.0509400103 
Abraham C, Bai L, Leube RE (2011) Synaptogyrin-dependent modulation of synaptic neurotransmission in Caenorhabditis elegans. Neuroscience 190:75-88. https://doi.org/10.1016/j. neuroscience.2011.05.069

Ann K, Kowalchyk JA, Loyet KM, Martin TF (1997) Novel $\mathrm{Ca}^{2+}$-binding protein (CAPS) related to UNC-31 required for $\mathrm{Ca}^{2+}$-activated exocytosis. J Biol Chem 272(32):19637-19640

Aravamudan B, Broadie K (2003) Synaptic drosophila UNC-13 is regulated by antagonistic G-protein pathways via a proteasome-dependent degradation mechanism. J Neurobiol 54(3):417-438. https://doi.org/10.1002/neu.10142

Arthur CP, Stowell MH (2007) Structure of synaptophysin: a hexameric MARVEL-domain channel protein. Structure 15(6):707714. https://doi.org/10.1016/j.str.2007.04.011

Augustin I, Rosenmund C, Sudhof TC, Brose N (1999) Munc13-1 is essential for fusion competence of glutamatergic synaptic vesicles. Nature 400(6743):457-461. https://doi.org/10.1038/22768

Augustin I, Korte S, Rickmann M, Kretzschmar HA, Sudhof TC, Herms JW et al (2001) The cerebellum-specific Munc13 isoform Munc13-3 regulates cerebellar synaptic transmission and motor learning in mice. J Neurosci 21(1):10-17

Avery L, Bargmann CI, Horvitz HR (1993) The Caenorhabditis elegans unc-31 gene affects multiple nervous system-controlled functions. Genetics 134(2):455-464

Bahler M, Greengard P (1987) Synapsin I bundles F-actin in a phosphorylation-dependent manner. Nature 326(6114):704-707. https ://doi.org/10.1038/326704a0

Basu J, Shen N, Dulubova I, Lu J, Guan R, Guryev O et al (2005) A minimal domain responsible for Munc13 activity. Nat Struct Mol Biol 12(11):1017-1018. https://doi.org/10.1038/nsmb1001

Berwin B, Floor E, Martin TF (1998) CAPS (mammalian UNC-31) protein localizes to membranes involved in dense-core vesicle exocytosis. Neuron 21(1):137-145

Betz A, Okamoto M, Benseler F, Brose N (1997) Direct interaction of the rat unc-13 homologue Munc13-1 with the $\mathrm{N}$ terminus of syntaxin. J Biol Chem 272(4):2520-2526

Betz A, Thakur P, Junge HJ, Ashery U, Rhee JS, Scheuss V et al (2001) Functional interaction of the active zone proteins Munc13-1 and RIM1 in synaptic vesicle priming. Neuron 30(1):183-196. https ://doi.org/10.1016/S0896-6273(01)00272-0

Binotti B, Jahn R, Chua JJ (2016) Functions of Rab proteins at presynaptic sites. Cells. https://doi.org/10.3390/cells5010007

Bloom O, Evergren E, Tomilin N, Kjaerulff O, Low P, Brodin L et al (2003) Colocalization of synapsin and actin during synaptic vesicle recycling. J Cell Biol 161(4):737-747. https://doi. org/10.1083/jcb.200212140

Bock JB, Matern HT, Peden AA, Scheller RH (2001) A genomic perspective on membrane compartment organization. Nature 409(6822):839-841. https://doi.org/10.1038/35057024

Bracher A, Weissenhorn W (2004) Crystal structure of the Habc domain of neuronal syntaxin from the squid Loligo pealei reveals conformational plasticity at its C-terminus. BMC Struct Biol 4:6. https://doi.org/10.1186/1472-6807-4-6

Brenner S (1974) The genetics of Caenorhabditis elegans. Genetics 77(1):71-94

Calakos N, Schoch S, Sudhof TC, Malenka RC (2004) Multiple roles for the active zone protein RIM1alpha in late stages of neurotransmitter release. Neuron 42(6):889-896. https://doi. org/10.1016/j.neuron.2004.05.014

Cesca F, Baldelli P, Valtorta F, Benfenati F (2010) The synapsins: key actors of synapse function and plasticity. Prog Neurobiol 91(4):313-348. https://doi.org/10.1016/j.pneurobio.2010.04.006

Charlie NK, Schade MA, Thomure AM, Miller KG (2006) Presynaptic $\mathrm{UNC}-31$ (CAPS) is required to activate the $\mathrm{G}$ alpha(s) pathway of the Caenorhabditis elegans synaptic signaling network. Genetics 172(2):943-961. https://doi.org/10.1534/genetics.105.049577
Cheng Y, Wang J, Wang Y, Ding M (2015) Synaptotagmin 1 directs repetitive release by coupling vesicle exocytosis to the Rab3 cycle. Elife. https://doi.org/10.7554/eLife.05118

Dalliere N, Bhatla N, Luedtke Z, Ma DK, Woolman J, Walker RJ et al (2016) Multiple excitatory and inhibitory neural signals converge to fine-tune Caenorhabditis elegans feeding to food availability. FASEB J 30(2):836-848. https://doi.org/10.1096/fj.15-279257

De Camilli P, Cameron R, Greengard P (1983) Synapsin I (protein I), a nerve terminal-specific phosphoprotein. I. Its general distribution in synapses of the central and peripheral nervous system demonstrated by immunofluorescence in frozen and plastic sections. $\mathrm{J}$ Cell Biol 96(5):1337-1354

De Camilli P, Benfenati F, Valtorta F, Greengard P (1990) The synapsins. Annu Rev Cell Biol 6:433-460. https://doi.org/10.1146/ annurev.cb.06.110190.002245

Delgado-Martinez I, Nehring RB, Sorensen JB (2007) Differential abilities of SNAP-25 homologs to support neuronal function. J Neurosci 27(35):9380-9391. https://doi.org/10.1523/Jneur osci.5092-06.2007

DiCaprio RA, Billimoria CP, Ludwar BC (2007) Information rate and spike-timing precision of proprioceptive afferents. J Neurophysiol 98(3):1706-1717. https://doi.org/10.1152/jn.00176.2007

Dulubova I, Khvotchev M, Liu S, Huryeva I, Sudhof TC, Rizo J (2007) Munc18-1 binds directly to the neuronal SNARE complex. Proc Natl Acad Sci U S A 104(8):2697-2702. https://doi.org/10.1073/ pnas.0611318104

Dybbs M, Ngai J, Kaplan JM (2005) Using microarrays to facilitate positional cloning: Identification of tomosyn as an inhibitor of neurosecretion. PLoS Genet 1(1):6-16. https://doi.org/10.1371/ journal.pgen.0010002

Eshkind LG, Leube RE (1995) Mice lacking synaptophysin reproduce and form typical synaptic vesicles. Cell Tissue Res 282(3):423-433

Evans GJ, Cousin MA (2005) Tyrosine phosphorylation of synaptophysin in synaptic vesicle recycling. Biochem Soc Trans 33(Pt 6):1350-1353. https://doi.org/10.1042/BST20051350

Farina M, van de Bospoort R, He E, Persoon CM, van Weering JR, Broeke JH et al (2015) CAPS-1 promotes fusion competence of stationary dense-core vesicles in presynaptic terminals of mammalian neurons. Elife. https://doi.org/10.7554/eLife.05438

Ferreira A, Han HQ, Greengard P, Kosik KS (1995) Suppression of synapsin II inhibits the formation and maintenance of synapses in hippocampal culture. Proc Natl Acad Sci U S A 92(20):9225-9229

Ferreira A, Kao HT, Feng J, Rapoport M, Greengard P (2000) Synapsin III: developmental expression, subcellular localization, and role in axon formation. J Neurosci 20(10):3736-3744

Fornasiero EF, Bonanomi D, Benfenati F, Valtorta F (2010) The role of synapsins in neuronal development. Cell Mol Life Sci 67(9):1383-1396. https://doi.org/10.1007/s00018-009-0227-8

Fujita Y, Shirataki H, Sakisaka T, Asakura T, Ohya T, Kotani H et al (1998) Tomosyn: a syntaxin-1-binding protein that forms a novel complex in the neurotransmitter release process. Neuron 20(5):905-915

Fujiwara T, Mishima T, Kofuji T, Chiba T, Tanaka K, Yamamoto A et al (2006) Analysis of knock-out mice to determine the role of HPC-1/syntaxin 1A in expressing synaptic plasticity. J Neurosci 26(21):5767-5776. https://doi.org/10.1523/JNEUR OSCI.0289-06.2006

Gallegos ME, Balakrishnan S, Chandramouli P, Arora S, Azameera A, Babushekar A et al (2012) The C. elegans rab family: identification, classification and toolkit construction. PLoS ONE 7(11):e49387. https://doi.org/10.1371/journal.pone.0049387

Geerts CJ, Mancini R, Chen N, Koopmans FTW, Li KW, Smit AB et al (2017) Tomosyn associates with secretory vesicles in neurons 
through its $\mathrm{N}$-and C-terminal domains. PLoS ONE. https://doi. org/10.1371/journal.pone.0180912

Gengyo-Ando K, Kamiya Y, Yamakawa A, Kodaira K, Nishiwaki K, Miwa J et al (1993) The C. elegans unc-18 gene encodes a protein expressed in motor neurons. Neuron 11(4):703-711

Geppert M, Goda Y, Hammer RE, Li C, Rosahl TW, Stevens CF et al (1994) Synaptotagmin I: a major $\mathrm{Ca}^{2+}$ sensor for transmitter release at a central synapse. Cell 79(4):717-727

Gerber SH, Rah JC, Min SW, Liu XR, de Wit H, Dulubova I et al (2008) Conformational switch of syntaxin-1 controls synaptic vesicle fusion. Science 321(5895):1507-1510. https://doi. org/10.1126/science. 1163174

Gracheva EO, Burdina AO, Holgado AM, Berthelot-Grosjean M, Ackley BD, Hadwiger G et al (2006) Tomosyn inhibits synaptic vesicle priming in Caenorhabditis elegans. PLoS Biol 4(8):e261. https://doi.org/10.1371/journal.pbio.0040261

Gracheva EO, Hadwiger G, Nonet ML, Richmond JE (2008) Direct interactions between C. elegans RAB-3 and Rim provide a mechanism to target vesicles to the presynaptic density. Neurosci Lett 444(2):137-142. https://doi.org/10.1016/j.neulet.2008.08.026

Gracheva EO, Maryon EB, Berthelot-Grosjean M, Richmond JE (2010) Differential regulation of synaptic vesicle tethering and docking by UNC-18 and TOM-1. Front Synaptic Neurosci 2:141. https:// doi.org/10.3389/fnsyn.2010.00141

Graham ME, Prescott GR, Johnson JR, Jones M, Walmesley A, Haynes LP et al (2011) Structure-function study of mammalian Munc18-1 and C. elegans UNC-18 implicates domain $3 b$ in the regulation of exocytosis. PLoS ONE 6(3):e17999. https://doi. org/10.1371/journal.pone.0017999

Grishanin RN, Klenchin VA, Loyet KM, Kowalchyk JA, Ann K, Martin TF (2002) Membrane association domains in $\mathrm{Ca}^{2+}$-dependent activator protein for secretion mediate plasma membrane and dense-core vesicle binding required for $\mathrm{Ca}^{2+}$-dependent exocytosis. J Biol Chem 277(24):22025-22034. https://doi.org/10.1074/ jbc.M201614200

Hammarlund M, Watanabe S, Schuske K, Jorgensen EM (2008) CAPS and syntaxin dock dense core vesicles to the plasma membrane in neurons. J Cell Biol 180(3):483-491. https://doi.org/10.1083/ jcb. 200708018

Hatsuzawa K, Lang T, Fasshauer D, Bruns D, Jahn R (2003) The R-SNARE motif of tomosyn forms SNARE core complexes with syntaxin 1 and SNAP-25 and down-regulates exocytosis. J Biol Chem 278(33):31159-31166. https://doi.org/10.1074/jbc. M305500200

Hilfiker S, Schweizer FE, Kao HT, Czernik AJ, Greengard P, Augustine GJ (1998) Two sites of action for synapsin domain $\mathrm{E}$ in regulating neurotransmitter release. Nat Neurosci 1(1):29-35. https:// doi.org/10.1038/229

Holt M, Varoqueaux F, Wiederhold K, Takamori S, Urlaub H, Fasshauer D et al (2006) Identification of SNAP-47, a novel Qbc-SNARE with ubiquitous expression. J Biol Chem 281(25):17076-17083. https://doi.org/10.1074/jbc.M513838200

Hu ZT, Tong XJ, Kaplan JM (2013) UNC-13L, UNC-13S, and Tomosyn form a protein code for fast and slow neurotransmitter release in Caenorhabditis elegans. Elife. https://doi.org/10.7554/ eLife.00967

Hubner K, Windoffer R, Hutter H, Leube RE (2002) Tetraspan vesicle membrane proteins: synthesis, subcellular localization, and functional properties. Int Rev Cytol 214:103-159

Hwang SB, Lee J (2003) Neuron cell type-specific SNAP-25 expression driven by multiple regulatory elements in the nematode Caenorhabditis elegans. J Mol Biol 333(2):237-247

Imig C, Min SW, Krinner S, Arancillo M, Rosenmund C, Sudhof TC et al (2014) The morphological and molecular nature of synaptic vesicle priming at presynaptic active zones (vol 84, pg
416, 2014). Neuron 84(4):882. https://doi.org/10.1016/j.neuro n.2014.11.003

Jockusch WJ, Speidel D, Sigler A, Sorensen JB, Varoqueaux F, Rhee JS et al (2007) CAPS-1 and CAPS-2 are essential synaptic vesicle priming proteins. Cell 131(4):796-808. https://doi.org/10.1016/j. cell.2007.11.002

Jung N, Haucke V (2007) Clathrin-mediated endocytosis at synapses. Traffic 8(9):1129-1136. https://doi.org/10.111 1/j.1600-0854.2007.00595.x

Kaeser PS, Kwon HB, Chiu CQ, Deng L, Castillo PE, Sudhof TC (2008) RIM1alpha and RIM1beta are synthesized from distinct promoters of the RIM1 gene to mediate differential but overlapping synaptic functions. J Neurosci 28(50):13435-13447. https://doi.org/10.1523/JNEUROSCI.3235-08.2008

Kaeser PS, Deng LB, Wang Y, Dulubova I, Liu XR, Rizo J et al (2011) RIM proteins tether $\mathrm{Ca}^{2+}$ channels to presynaptic active zones via a direct PDZ-domain interaction. Cell 144(2):282295. https://doi.org/10.1016/j.cell.2010.12.029

Kao HT, Porton B, Hilfiker S, Stefani G, Pieribone VA, DeSalle R et al (1999) Molecular evolution of the synapsin gene family. J Exp Zool 285(4):360-377

Katz B (1971) Quantal mechanism of neural transmitter release. Science 173(3992):123-126

Katz B (1979) Elementary components of synaptic transmission. Naturwissenschaften 66(12):606-610

Kohn RE, Duerr JS, McManus JR, Duke A, Rakow TL, Maruyama $\mathrm{H}$ et al (2000) Expression of multiple UNC-13 proteins in the Caenorhabditis elegans nervous system. Mol Biol Cell 11(10):3441-3452

Koushika SP, Richmond JE, Hadwiger G, Weimer RM, Jorgensen EM, Nonet ML (2001) A post-docking role for active zone protein Rim. Nat Neurosci 4(10):997-1005. https://doi. org/10.1038/nn732

Lackner MR, Nurrish SJ, Kaplan JM (1999) Facilitation of synaptic transmission by EGL-30 G(q)alpha and EGL-8 PLC beta: DAG binding to UNC-13 is required to stimulate acetylcholine release. Neuron 24(2):335-346. https://doi.org/10.1016/S0896 $-6273(00) 80848-X$

Lemmon MA (2008) Membrane recognition by phospholipid-binding domains. Nat Rev Mol Cell Biol 9(2):99-111. https://doi. org/10.1038/nrm2328

Li X, Rosahl TW, Sudhof TC, Francke U (1995) Mapping of synapsin II (SYN2) genes to human chromosome $3 p$ and mouse chromosome 6 band F. Cytogenet Cell Genet 71(3):301-305

Li W, Ma C, Guan R, Xu YB, Tomchick DR, Rizo J (2011) The crystal structure of a Munc13 C-terminal module exhibits a remarkable similarity to vesicle tethering factors. Structure 19(10):1443-1455. https://doi.org/10.1016/j. str.2011.07.012

Ma C, Li W, Xu YB, Rizo J (2011) Munc13 mediates the transition from the closed syntaxin-Munc18 complex to the SNARE complex. Nat Struct Mol Biol 18(5):542-U206. https://doi. org/10.1038/nsmb.2047

Madison JM, Nurrish S, Kaplan JM (2005) UNC-13 interaction with syntaxin is required for synaptic transmission. Curr Biol 15(24):2236-2242. https://doi.org/10.1016/j.cub.2005.10.049

Mahoney TR, Liu Q, Itoh T, Luo S, Hadwiger G, Vincent R et al (2006) Regulation of synaptic transmission by RAB-3 and RAB-27 in Caenorhabditis elegans. Mol Biol Cell 17(6):2617-2625. https ://doi.org/10.1091/mbc.E05-12-1170

Martin TF (2003) Tuning exocytosis for speed: fast and slow modes. Biochim Biophys Acta 1641(2-3):157-165

Maruyama H, Rakow TL, Maruyama IN (2001) Synaptic exocytosis and nervous system development impaired in Caenorhabditis elegans unc-13 mutants. Neuroscience 104(2):287-297 
Masuda ES, Huang BC, Fisher JM, Luo Y, Scheller RH (1998) Tomosyn binds t-SNARE proteins via a VAMP-like coiled coil. Neuron 21(3):479-480

Mathews EA, Mullen GP, Crowell JA, Duerr JS, McManus JR, Duke A et al (2007) Differential expression and function of synaptotagmin 1 isoforms in Caenorhabditis elegans. Mol Cell Neurosci 34(4):642-652. https://doi.org/10.1016/j.mcn.2007.01.009

McEwen JM, Kaplan JM (2008) UNC-18 promotes both the anterograde trafficking and synaptic function of syntaxin. Mol Biol Cell 19(9):3836-3846. https://doi.org/10.1091/mbc.E08-02-0160

McEwen JM, Madison JM, Dybbs M, Kaplan JM (2006) Antagonistic regulation of synaptic vesicle priming by Tomosyn and UNC-13. Neuron 51(3):303-315. https://doi.org/10.1016/j.neuro n.2006.06.025

McMahon HT, Bolshakov VY, Janz R, Hammer RE, Siegelbaum SA, Sudhof TC (1996) Synaptophysin, a major synaptic vesicle protein, is not essential for neurotransmitter release. Proc Natl Acad Sci U S A 93(10):4760-4764

Mishima T, Fujiwara T, Sanada M, Kofuji T, Kanai-Azuma M, Akagawa K (2014) Syntaxin 1B, but not Syntaxin 1A, is necessary for the regulation of synaptic vesicle exocytosis and of the readily releasable pool at central synapses. PLoS ONE. https://doi. org/10.1371/journal.pone.0090004

Munson M, Bryant NJ (2009) A role for the syntaxin N-terminus. Biochem J 418(1):e1-e3. https://doi.org/10.1042/BJ20082389

Neher E, Sakaba T (2008) Multiple roles of calcium ions in the regulation of neurotransmitter release. Neuron 59(6):861-872. https:// doi.org/10.1016/j.neuron.2008.08.019

Nelson JC, Stavoe AK, Colon-Ramos DA (2013) The actin cytoskeleton in presynaptic assembly. Cell Adhes Migr 7(4):379-387. https://doi.org/10.4161/cam.24803

Nonet ML (1999) Visualization of synaptic specializations in live $C$. elegans with synaptic vesicle protein-GFP fusions. J Neurosci Methods 89(1):33-40

Nonet ML, Grundahl K, Meyer BJ, Rand JB (1993) Synaptic function is impaired but not eliminated in C. Elegans mutants lacking synaptotagmin. Cell 73(7):1291-1305. https://doi.org/10.1016/00928674(93)90357-V

Nonet ML, Staunton JE, Kilgard MP, Fergestad T, Hartwieg E, Horvitz HR et al (1997) Caenorhabditis elegans rab-3 mutant synapses exhibit impaired function and are partially depleted of vesicles. J Neurosci 17(21):8061-8073

Nonet ML, Saifee O, Zhao H, Rand JB, Wei L (1998) Synaptic transmission deficits in Caenorhabditis elegans synaptobrevin mutants. J Neurosci 18(1):70-80

Nystuen AM, Schwendinger JK, Sachs AJ, Yang AW, Haider NB (2007) A null mutation in VAMP1/synaptobrevin is associated with neurological defects and prewean mortality in the lethalwasting mouse mutant. Neurogenetics 8(1):1-10. https://doi. org/10.1007/s10048-006-0068-7

Ogawa H, Harada S, Sassa T, Yamamoto H, Hosono R (1998) Functional properties of the unc-64 gene encoding a Caenorhabditis elegans syntaxin. J Biol Chem 273(4):2192-2198

Pan PY, Cai Q, Lin L, Lu PH, Duan SM, Sheng ZH (2005) SNAP29-mediated modulation of synaptic transmission in cultured hippocampal neurons. J Biol Chem 280(27):25769-25779. https:// doi.org/10.1074/jbc.M502356200

Pang ZP, Melicoff E, Padgett D, Liu Y, Teich AF, Dickey BF et al (2006) Synaptotagmin-2 is essential for survival and contributes to $\mathrm{Ca}^{2+}$ triggering of neurotransmitter release in central and neuromuscular synapses. J Neurosci 26(52):13493-13504. https:// doi.org/10.1523/JNEUROSCI.3519-06.2006

Park S, Bin NR, Michael Rajah M, Kim B, Chou TC, Kang SY et al (2016) Conformational states of syntaxin-1 govern the necessity of $\mathrm{N}$-peptide binding in exocytosis of PC12 cells and
Caenorhabditis elegans. Mol Biol Cell 27(4):669-685. https:// doi.org/10.1091/mbc.E15-09-0638

Pieribone VA, Shupliakov O, Brodin L, Hilfiker-Rothenfluh S, Czernik AJ, Greengard P (1995) Distinct pools of synaptic vesicles in neurotransmitter release. Nature 375(6531):493-497. https://doi. org/10.1038/375493a0

Porton B, Wetsel WC, Kao HT (2011) Synapsin III: role in neuronal plasticity and disease. Semin Cell Dev Biol 22(4):416-424. https ://doi.org/10.1016/j.semcdb.2011.07.007

Ramirez DMO, Kavalali ET (2011) Differential regulation of spontaneous and evoked neurotransmitter release at central synapses. Curr Opin Neurobiol 21(2):275-282. https://doi.org/10.1016/j. conb.2011.01.007

Renden R, Berwin B, Davis W, Ann K, Chin CT, Kreber R et al (2001) Drosophila CAPS is an essential gene that regulates dense-core vesicle release and synaptic vesicle fusion. Neuron 31(3):421-437

Rettig J, Neher E (2002) Emerging roles of presynaptic proteins in $\mathrm{Ca}^{++}$-triggered exocytosis. Science 298(5594):781-785. https:// doi.org/10.1126/science. 1075375

Richmond J (2005) Synaptic function. WormBook. https://doi. org/10.1895/wormbook.1.69.1

Richmond JE, Davis WS, Jorgensen EM (1999) UNC-13 is required for synaptic vesicle fusion in C. elegans. Nat Neurosci 2(11):959-964

Rizo J, Sudhof TC (1998) $C_{2}$-domains, structure and function of a universal $\mathrm{Ca}^{2+}$-binding domain. J Biol Chem 273(26):15879-15882

Rizo J, Sudhof TC (2002) Snares and Munc18 in synaptic vesicle fusion. Nat Rev Neurosci 3(8):641-653. https://doi.org/10.1038/ nrn898

Rosenmund C, Sigler A, Augustin I, Reim K, Brose N, Rhee JS (2002) Differential control of vesicle priming and short-term plasticity by Munc13 isoforms. Neuron 33(3):411-424. https://doi. org/10.1016/S0896-6273(02)00568-8

Ruvinsky I, Ohler U, Burge CB, Ruvkun G (2007) Detection of broadly expressed neuronal genes in C. elegans. Dev Biol 302(2):617626. https://doi.org/10.1016/j.ydbio.2006.09.014

Sadakata T, Washida M, Furuichi T (2007a) Alternative splicing variations in mouse CAPS2: differential expression and functional properties of splicing variants. BMC Neurosci 8:25. https://doi. org/10.1186/1471-2202-8-25

Sadakata T, Washida M, Iwayama Y, Shoji S, Sato Y, Ohkura T et al (2007b) Autistic-like phenotypes in Cadps2-knockout mice and aberrant CADPS2 splicing in autistic patients. J Clin Invest 117(4):931-943. https://doi.org/10.1172/JCI29031

Sadakata T, Washida M, Morita N, Furuichi T (2007c) Tissue distribution of $\mathrm{Ca}^{2+}$-dependent activator protein for secretion family members CAPS1 and CAPS2 in mice. J Histochem Cytochem 55(3):301-311. https://doi.org/10.1369/jhc.6A7033.2006

Saifee O, Wei LP, Nonet ML (1998) The Caenorhabditis elegans unc64 locus encodes a syntaxin that interacts genetically with synaptobrevin. Mol Biol Cell 9(6):1235-1252

Sandoval GM, Duerr JS, Hodgkin J, Rand JB, Ruvkun G (2006) A genetic interaction between the vesicular acetylcholine transporter VAChT/UNC-17 and synaptobrevin/SNB-1 in C. elegans. Nat Neurosci 9(5):599-601. https://doi.org/10.1038/nn1685

Sassa T, Harada S, Ogawa H, Rand JB, Maruyama IN, Hosono R (1999) Regulation of the UNC-18-Caenorhabditis elegans syntaxin complex by UNC-13. J Neurosci 19(12):4772-4777

Schindelman G, Whittaker AJ, Thum JY, Gharib S, Sternberg PW (2006) Initiation of male sperm-transfer behavior in Caenorhabditis elegans requires input from the ventral nerve cord. BMC Biol. https://doi.org/10.1186/1741-7007-4-26

Schluter OM, Khvotchev M, Jahn R, Sudhof TC (2002) Localization versus function of Rab3 proteins. Evidence for a 
common regulatory role in controlling fusion. J Biol Chem 277(43):40919-40929. https://doi.org/10.1074/jbc.M203704200

Schoch S, Deak F, Konigstorfer A, Mozhayeva M, Sara Y, Sudhof TC et al (2001) SNARE function analyzed in synaptobrevin/ VAMP knockout mice. Science 294(5544):1117-1122. https:// doi.org/10.1126/science.1064335

Schoch S, Castillo PE, Jo T, Mukherjee K, Geppert M, Wang Y et al (2002) RIM1 alpha forms a protein scaffold for regulating neurotransmitter release at the active zone. Nature 415(6869):321-326. https://doi.org/10.1038/415321a

Sieburth D, Ch'ng Q, Dybbs M, Tavazoie M, Kennedy S, Wang D et al (2005) Systematic analysis of genes required for synapse structure and function. Nature 436(7050):510-517. https://doi. org/10.1038/nature03809

Sieburth D, Madison JM, Kaplan JM (2007) PKC-1 regulates secretion of neuropeptides. Nat Neurosci 10(1):49-57. https://doi. org/10.1038/nn1810

Speidel D, Varoqueaux F, Enk C, Nojiri M, Grishanin RN, Martin TF et al (2003) A family of $\mathrm{Ca}^{2+}$-dependent activator proteins for secretion: comparative analysis of structure, expression, localization, and function. J Biol Chem 278(52):52802-52809. https:// doi.org/10.1074/jbc.M304727200

Speidel D, Bruederle CE, Enk C, Voets T, Varoqueaux F, Reim K et al (2005) CAPS1 regulates catecholamine loading of large densecore vesicles. Neuron 46(1):75-88. https://doi.org/10.1016/j. neuron.2005.02.019

Stavoe AK, Nelson JC, Martinez-Velazquez LA, Klein M, Samuel AD, Colon-Ramos DA (2012) Synaptic vesicle clustering requires a distinct MIG-10/Lamellipodin isoform and ABI-1 downstream from Netrin. Genes Dev 26(19):2206-2221. https://doi. org/10.1101/gad.193409.112

Stenmark H, Olkkonen VM (2001) The rab GTPase family. Genome Biol 2(5):reviews3007.1-3007.7

Stevens DR, Wu ZX, Matti U, Junge HJ, Schirra C, Becherer U et al (2005) Identification of the minimal protein domain required for priming activity of Munc13-1. Curr Biol 15(24):2243-2248. https://doi.org/10.1016/j.cub.2005.10.055

Sudhof TC (1995) The synaptic vesicle cycle: a cascade of proteinprotein interactions. Nature 375(6533):645-653. https://doi. org/10.1038/375645a0

Sudhof TC (2004) The synaptic vesicle cycle. Annu Rev Neurosci 27:509-547. https://doi.org/10.1146/annurev.neuro.26.04100 2.131412

Sudhof TC (2013) Neurotransmitter release: the last millisecond in the life of a synaptic vesicle. Neuron 80(3):675-690. https://doi. org/10.1016/j.neuron.2013.10.022

Sun J, Pang ZP, Qin D, Fahim AT, Adachi R, Sudhof TC (2007) A dual- $\mathrm{Ca}^{2+}$-sensor model for neurotransmitter release in a central synapse. Nature 450(7170):676-682. https://doi.org/10.1038/ nature 06308

Sun Y, Hu Z, Goeb Y, Dreier L (2013) The F-box protein MEC-15 (FBXW9) promotes synaptic transmission in GABAergic motor neurons in C. elegans. PLoS ONE 8(3):e59132. https://doi. org/10.1371/journal.pone.0059132

Takamori S, Holt M, Stenius K, Lemke EA, Gronborg M, Riedel D et al (2006) Molecular anatomy of a trafficking organelle. Cell 127(4):831-846. https://doi.org/10.1016/j.cell.2006.10.030

Takei Y, Harada A, Takeda S, Kobayashi K, Terada S, Noda T et al (1995) Synapsin I deficiency results in the structural change in the presynaptic terminals in the murine nervous system. J Cell Biol 131(6 Pt 2):1789-1800

Tandon A, Bannykh S, Kowalchyk JA, Banerjee A, Martin TF, Balch WE (1998) Differential regulation of exocytosis by calcium and CAPS in semi-intact synaptosomes. Neuron 21(1):147-154

Teng FYH, Wang Y, Tang BL (2001) The syntaxins. Genome Biol 2(11):reviews3012.1-3012.7

van Steveninck RRD, Laughlin SB (1996) The rate of information transfer at graded-potential synapses. Nature 379(6566):642645. https://doi.org/10.1038/379642a0

Walent JH, Porter BW, Martin TF (1992) A novel 145 kd brain cytosolic protein reconstitutes $\mathrm{Ca}^{2+}$-regulated secretion in permeable neuroendocrine cells. Cell 70(5):765-775

Wang Y, Sudhof TC (2003) Genomic definition of RIM proteins: evolutionary amplification of a family of synaptic regulatory proteins. Genomics 81(2):126-137

Wang Y, Okamoto M, Schmitz F, Hofmann K, Sudhof TC (1997) Rim is a putative Rab3 effector in regulating synaptic-vesicle fusion. Nature 388(6642):593-598

Watanabe S, Liu Q, Davis MW, Hollopeter G, Thomas N, Jorgensen NB et al (2013) Ultrafast endocytosis at Caenorhabditis elegans neuromuscular junctions. Elife. https://doi.org/10.7554/eLife .00723

Weimer RM, Richmond JE, Davis WS, Hadwiger G, Nonet ML, Jorgensen EM (2003) Defects in synaptic vesicle docking in unc-18 mutants. Nat Neurosci 6(10):1023-1030. https://doi.org/10.1038/ nn1118

Xu J, Pang ZP, Shin OH, Sudhof TC (2009) Synaptotagmin-1 functions as a $\mathrm{Ca}^{2+}$ sensor for spontaneous release. Nat Neurosci 12(6):759-766. https://doi.org/10.1038/nn.2320

Yamashita M, Iwasaki K, Doi M (2009) The non-neuronal syntaxin SYN-1 regulates defecation behavior and neural activity in $C$. elegans through interaction with the Munc13-like protein AEX1. Biochem Biophys Res Commun 378(3):404-408. https://doi. org/10.1016/j.bbrc.2008.11.064

Yu SC, Klosterman SM, Martin AA, Gracheva EO, Richmond JE (2013) Differential roles for snapin and synaptotagmin in the synaptic vesicle cycle. PLoS ONE 8(2):e57842. https://doi. org/10.1371/journal.pone.0057842

Zhou KM, Stawicki TM, Goncharov A, Jin YS (2013) Position of UNC-13 in the active zone regulates synaptic vesicle release probability and release kinetics. Elife. https://doi.org/10.7554/ eLife. 01180 